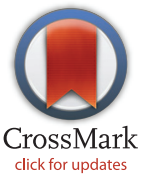

G OPEnACCESS

Citation: Kinkel H-T, Karmacharya D, Shakya J, Manandhar S, Panthi S, Karmacharya P, et al. (2015) Prevalence of HIV, Hepatitis B and C Infections and an Assessment of HCV-Genotypes and Two IL28B SNPs among People Who Inject Drugs in Three Regions of Nepal. PLoS ONE 10(8): e0134455. doi:10.1371/journal.pone. 0134455

Editor: Jason Blackard, University of Cincinnati College of Medicine, UNITED STATES

Received: November 6, 2014

Accepted: July 10, 2015

Published: August 11, 2015

Copyright: @ 2015 Kinkel et al. This is an open access article distributed under the terms of the Creative Commons Attribution License, which permits unrestricted use, distribution, and reproduction in any medium, provided the original author and source are credited.

Data Availability Statement: All relevant data are available from the Center for Molecular Dynamics Nepal website (http://cmdn.org.np/main/publication. php).

Funding: This work was supported by NepaliGerman Project "HIV prevention for the high-risk group of injecting drug users" and commissioned by the German Federal Ministry of Economic Cooperation and Development (BMZ). The analysis, results and recommendations in this paper represent the opinion of the authors and are not necessarily
RESEARCH ARTICLE

\section{Prevalence of HIV, Hepatitis B and C Infections and an Assessment of HCV- Genotypes and Two IL28B SNPs among People Who Inject Drugs in Three Regions of Nepal}

\begin{abstract}
Hans-Tilmann Kinkel ${ }^{1}$, Dibesh Karmacharya ${ }^{2}$, Jivan Shakya ${ }^{2}$, Sulochana Manandhar ${ }^{2}$, Santosh Panthi ${ }^{2}$, Prajwola Karmacharya ${ }^{2,3}$, Deepika Sitaula ${ }^{4}$, Reenu Thapaliya ${ }^{3}$, Prawachan K. C. ${ }^{5}$, Apurva Rai ${ }^{5}$, Sameer Dixit ${ }^{2 *}$
\end{abstract}

1 Gesellschaft für Internationale Zusammenarbeit (GIZ), HRP, PO.Box 1457, Kathmandu, Nepal, 2 Center for Molecular Dynamics Nepal, Kathmandu, Nepal, 3 Trichandra Multiple College, Kathmandu, Nepal, 4 St. Xavier College, Kathmandu, Nepal, 5 SPARSHA Nepal, Latitpur, Nepal

*s.dixit@cmdn.org

\section{Abstract}

As part of a comprehensive health care programme for people who use drugs in Nepal, HIV and viral hepatitis $B$ and $C$ status-including risk factors, HCV-genotypes and co-infections -as well as two IL28B Single-nucleotide polymorphisms (SNPs) were assessed for a random sample of 401 people who inject drugs in three regions of Nepal: mid-western Terrai (Nepalgunj), the eastern region (Dharan, Biratnagar) and the central region (Kathmandu, Lalitpur and Chitwan). Individuals were included who showed at least a minimum of health care seeking behaviour. This latter criterion was defined by being registered with any organisation offering health services. The average age of the participants was $30.5 \mathrm{yrs}$, and the average length of intravenous drug use was $8.5 \mathrm{yrs}$. The prevalence rates of HBsAg, antiHIV antibodies and HCV-RNA were $3.5 \%, 13.8 \%$ and $41.9 \%$, respectively. Spontaneous $\mathrm{HCV}$ clearance was evident in $16 \%$ of all of those who tested positive for anti-HCV antibodies. Independent risk factors for HCV-RNA positivity were age, gender, geographical region, duration of injecting drug use, history of imprisonment and HIV co-infection. In the age group $\leq 24 \mathrm{yrs}$, the rate of spontaneous HCV clearance was $43.5 \%$. Overall, $59.8 \%$ of $\mathrm{HCV}$ infections were caused by HCV genotype 3 and $40.2 \%$ by HCV genotype 1 . No other HCV genotypes were identified in this study. The IL28B SNP rs 12979860 and rs 8099917 were identified in 122 patients, and $75.4 \%$ of all participants had both favourable genotypes rs $12979860 \mathrm{C} / \mathrm{C}$ and rs8099917 T/T. 
representative of the position of the Deutsche Gesellschaft für Internationale Zusammenarbeit (GIZ) GmbH (www.giz.de; www.mohp.gov.np). No individuals employed or contracted by the funders (other than the named authors) played any role in: study design, data collection and analysis, decision to publish, or preparation of the manuscript.

Competing Interests: The authors have declared that no competing interests exist.

\section{Introduction}

It has been estimated that 50,000 individuals (approximately $0.3 \%$ of the total adult population) inject drugs in Nepal with a significant increase in this figure occurring in recent years [1]. The overwhelming majority of people who inject drugs are young men who inject a pharmaceutical combination of buprenorphine, diazepam and a sedating antihistamine. Heroin use is less common, but does occur [2].

In several urban centres in Nepal, there have been substantial improvements in health care services for people who inject drugs. In particular, opioid substitution therapy, needle and syringe programmes, as well as HIV care and antiretroviral therapy have become more accessible. With these interventions, HIV prevalence has decreased below $10 \%$ among people who inject drugs in Nepal [3].

Besides the risk of HIV, people who inject drugs are at high risk of several medical and social harms, such as infection with viral hepatitis B (HBV) and C (HCV), tuberculosis (TB), sexually transmitted infections, mental disorders, and social exclusion. After many years of focussing almost exclusively on combatting HIV, chronic liver disease-and particularly chronic hepatitis $\mathrm{C}$-has become one of the leading causes of mortality for people with a history or current pattern of injecting drug use in many countries [4-7].

$\mathrm{HCV}$ is transmitted through blood contact including unsafe injection practices in medical and non-medical (e.g. injecting drug use and tattooing) contexts. Sexual transmission of HCV is relevant among people living with HIV [8]. In $50-80 \%$ of cases, HCV can lead to chronic hepatitis and this causes fibrosis, cirrhosis and hepatocellular carcinoma within 10-30 years in up to $30 \%$ of patients [9]. In low resource settings, pegylated interferon $\alpha$ plus ribavirin (pegIFN/RBV) is the standard treatment. However, the response to treatment with pegIFN/ RBV depends on the viral genotype (HCV-GT) and viral load. In addition to viral factors, host factors also determine the likelihood of achieving a sustained virologic response (SVR) when treating chronic hepatitis $\mathrm{C}$ with pegIFN/RBV. Two single-nucleotide polymorphisms (SNP) IL28B rs12979860 and rs8099917-determine the likelihood of spontaneous viral clearance and SVR with pegIFN/RBV-treatment. Homozygote carriers of cytosine (CC) at position rs12979860, and thymin (TT) at position rs8099917 have a much higher likelihood of spontaneous clearance and achieving SVR with pegIFN/RBV treatment. The higher rate of SVR in Asian patients correlates with high rates of IL28B rs12979860-CC and rs8099917-TT in this part of the world [10-13].

Little is known about HCV prevalence rates in Nepal. While it is low in the general population [14-21], two studies have suggested that the prevalence of anti-HCV antibodies among people with a past and/or current pattern of injecting drug use is around $80 \%$ to $85.5 \%$ for men and around 15\% for women [22-24]. To the best of our knowledge, no systematic assessment of HCV prevalence in Nepal has ever been published with regard to HCV-RNA or genotyping. IL28B-data have been published for several Asian countries [13, 25-30], but there is a lack of published data for Nepal.

Hepatitis B is transmitted vertically, sexually or through blood contact. Chronicity develops in $90 \%$ of infants infected with HBV but only $5 \%$ of people infected during adulthood. Nepal has the lowest prevalence of hepatitis B in Asia with an HBsAg carrier rate of 0.9\% [31]. Apart from a 2011 study on young women, no data on the prevalence of HBV among people who use drugs have been published in Nepal in the last 15 years. In the 2011 study, 13.4\% of women had previous exposure to $\mathrm{HBV}$ (anti-HBc antibodies) and $0.5 \%$ were currently infected (HBsAg) [24].

The main objective of this study was to assess the prevalence rates of HIV, HCV and HBV as well as co- and triple-infection patterns, $\mathrm{HCV}$ genotypes and two IL28B-SNPs among a 
random sample of 401 people who inject drugs and are registered with an organisation providing health care in 3 regions in Nepal. The study was embedded in a comprehensive programme to strengthen healthcare for people who use drugs in Nepal. Its results can be used to tailor a country-specific response to viral hepatitis for people who inject drugs.

\section{Materials and Methods}

In Nepal, all organisations providing health services to people who use drugs are organised under the umbrella group "Recovering Nepal". The organisations working in the (1) mid-western region Terrai (Nepalgunj), (2) eastern region (Dharan, Biratnagar), and (3) central region (Kathmandu, Lalitpur and Chitwan) were asked to participate in the study. All but one organisation from Kathmandu consented. The organisations gave each patient a code number and then submitted a list of 800 numbers corresponding to their registered clients. Using Microsoft Excel version 2007, a random sample of 480 participants were selected from this list to be included in this cross-sectional/prevalence study. Inclusion criteria were (1) current or past i.v. drug use that fulfils the ICD-10-criteria of opioid dependence, (2) being registered with a "Recovering Nepal"-affiliated organisation and (3) being able and willing to give informed consent. Exclusion criteria were: (1) impossible venepuncture and (2) current or past pharmacological treatment of HCV infection.

Of the 480 initially selected participants, 412 were successfully contacted and enrolled into the study. Eleven of these individuals were subsequently excluded from the analysis because they did not engage in i.v. drug use. As a consequence, 401 participants (301 males, 99 females and 1 transgender who is reported as female based on her own gender definition.) were included in the final analysis. None of the exclusion criteria applied to these randomly selected participants.

The required sample size was calculated for the sub groups, (1) female, (2) male, (3) the eastern region, (4) the mid-west region, (5) Lalitpur and (6) Kathmandu. Lalitpur and Kathmandu are situated in the central valley. Using Raosoft, a sample size of 84 was computed for subgroups 1, 3, 4, 5 and 6 based on an expected HCV prevalence of $15-85 \%$. A desired precision of $10 \%$ was given for the prevalence range of $20-80 \%$; the desired precision was $7.5 \%$ in the ranges of $15-20 \%$ and $80-85 \%$. The required confidence interval was $95 \%$ (95\% CI).

In confidential one-to-one interviews, trained Nepali counsellors asked participants about their age, gender, length of i.v. drug use as well as their history of sharing injection equipment, history of imprisonment, engagement in sex work and tattooing.

Lab technicians drew $5 \mathrm{ml}$ of venous blood using $5 \mathrm{ml}$ EDTA tubes. This sample was used to determine anti-HIV, anti-HCV, anti-HBs, anti-HBc antibodies, HBsAg, HCV-RNA and HCV-GT.

Assessment of IL28B SNPs investigated the influence of two IL28B SNPs on the natural course of an HCV infection. Participants living with anti-HCV antibodies were asked to provide a second sample of $5 \mathrm{ml}$ EDTA blood once their HCV-status was available; 122 participants were reached and consented to this second step.

An accelerated schedule of HBV-vaccination was offered to all participants who were found to be susceptible to HBV, and all participants living with HIV, HBV or HCV were referred to clinical centres for further assessment. Participants living with HCV were invited to participate in a separate treatment study, which is currently underway.

HIV was diagnosed according to the national standard protocol and employed serial testing, starting with the Determine HIV rapid test (Alere Medical, Japan). In instances with a positive result, this testing was followed by the Unigold HIV rapid test (Trinity Biotech, Ireland). When the results were discordant, the Tridot HIV test (J. Mitra\&Co., India) was used as to confirm. 
HBV was diagnosed using the Determine HBsAg rapid test (Alere Medical, Japan). This was confirmed by ELISA (Human Diagnostics, Germany). Where results were discordant, the HBV-5 Panel test card from Lumiquick was used as the tie-breaker. Anti-HBc and anti-HBs antibodies were determined with ELISA (Human Diagnostics, Germany). Anti-HCV antibodies were screened using the $4^{\text {th }}$ generation HCV rapid test HCV TRI-DOT (J. Mitra\&Co., India) and were confirmed by ELISA (Human Diagnostics, Germany).

The isolation of RNA and RT- PCR was carried out as follows: total RNA was isolated from patients' serum using the Spin Star viral nucleic acid kit 1.0 (ADT Biotech Sdn Bhd, Malaysia) according to the manufacturer's instructions. RT-PCR was performed using a two-step RT-PCR. First strand synthesis was performed using the SuperScript II RT-PCR System (Invitrogen, USA) in a $21 \mu \mathrm{l}$ reaction volume containing $8 \mu \mathrm{l}$ extracted RNA, $50 \mathrm{ng}$ random hexamers, $1 \mu \mathrm{l}$ dNTPs mix (10 mM), $9 \mu \mathrm{l}$ RT buffer and 50 unit superscript II reverse transcriptase. Second strand synthesis was performed in a $25 \mu \mathrm{l}$ reaction volume using QIAGEN multiplex PCR master mix (\# 206143), $0.6 \mathrm{mM}$ sense and antisense primers and $1 \mu \mathrm{l} \mathrm{cDNA}$. The primers targeting the 5'UTR region as per [32] were forward (DM 50) 5'-CTCGCAAGCACCCTAT CAGG-3' and reverse (DM 51) 5'-GAAAGCGTCTAGCCATGGCGTTAGT-3'. The DNA amplification protocol consists of pre incubation at $95^{\circ} \mathrm{C}$ for $15 \mathrm{~min}$ followed by $40 \mathrm{cycles}$ each of denaturation at $94^{\circ} \mathrm{C}$ for $15 \mathrm{~s}$, annealing at $55^{\circ} \mathrm{C}$ for $30 \mathrm{~s}$, and extension at $72^{\circ} \mathrm{C}$ for $10 \mathrm{~min}$. The last cycle was followed by a $10 \mathrm{~min}$ extension at $72^{\circ} \mathrm{C}$. The PCR products were analysed by agarose gel electrophoresis. The PCR products of samples showing the expected product size were purified using the ExoSAP-IT PCR product clean up kit (Affymetrix, USA). The purified products were DNA sequenced using the Big Dye Terminator Version 3.1 Cycle Sequencing Kit (Applied Biosystems, USA) with the forward primer DM50. The cycle-sequenced products were purified using the Big Dye X-terminator Kit (Applied Biosystems USA) and analysed in an ABI-3730 genetic analyser (Applied Biosystems, USA). The resulting sequence ends of raw data were trimmed to the reading frame. A BLASTN database search was used to identify the specific genotype.

Phylogenetic Analysis: The HCV isolates were phylogenetically characterized to trace their genetic relatedness with other each other as well as to those from neighbouring countries India, China. Various genotypes of HCV isolates from Thailand as well were used for comparison. A phylogenetic tree was constructed based on their 5UTR region sequence data using MEGA 6.0. A bootstrap re-sampling process (1,000 replications) using the neighbour-joining method was employed to assess the robustness of individual phylogeny nodes.

For IL28B SNP assessment, DNA was extracted from EDTA blood using the DNeasy blood and tissue kit (Qiagen, Germany) according to the manufacturer's protocol. IL28B SNP genotyping at rs8099917 was carried out using a predesigned TaqMan SNP Genotyping assay (Applied Biosystems, USA) with primers TTGTCACTGTTCCTCCTTTTGTTTT and GGCCCTAACTGATACGCTATAATTAAA. The SNP genotyping at rs12979860 was carried out using a customised TaqMan SNP genotyping assay (Applied Biosystems, USA) that used the primers TGCCTGTCGTGTACTGAACCA and GAGCGCGGAGTGCAATTC as well as the TaqMan probes VIC-TGGTTCGCGCCTTC-MGB and 6FAM-CTGGTTCACGCCT TC-MGB. The RT-PCR was carried out using Primer Design's lyophilized 2X qPCR mastermix in a $25 \mu \mathrm{l}$ reaction mix following the manufacturer's protocol. RT-PCR was carried out with the thermocycling program of one step at $95^{\circ} \mathrm{C}$ for $15 \mathrm{~min}$ followed by 50 cycles of $92^{\circ} \mathrm{C}$ for 15 $s$ and data collection at $60^{\circ} \mathrm{C}$ for $1 \mathrm{~min}$.

Excel 7 and SPSS version 22 were used for the statistical analysis of the data. The statistical significance of the analysed frequencies was determined using a $\chi 2$-test as well as Fisher's excact test for any absolute frequency $\leq 10$. Student's $t$-test was used to analyse the means of interval variables. Logistic regression was used to measure the relationship between categorical 
dependent variables and independent variables. Nagelkerke's $\mathrm{R}^{2}$, Hosmer and Lemeshow test as well as the Wald criterion were used to assess the validity of the logistic regression models. $\mathrm{P}$-values $<0.05$ were considered to be statistically significant.

\section{Ethics information}

The study was divided into three sub-studies-each received separate ethical approval from the National Health Research Council of Nepal (NHRC). The study code 1432 (02 June 2013) included men in all regions, the study code 277 (01 September 2013) included females and the study 888 (29 Jan 2014) referred to the IL28B SNP assessment.

In keeping with the procedures approved by the National Health Research Council (NHRC), all participants were required to give their written consent to participate in the study. The consent and confidentiality declaration was read to each participant in a confidential oneto-one session and was signed (or in case of illiteracy marked with a fingerprint) by all participants. The consent to test for HIV antibodies was obtained separately following pre-test counselling by a counsellor trained according to the national guidelines for HIV counsellors. Participation in the study was also possible for participants who refused the HIV test. Asides from the testing for HIV antibodies, these individuals were included in all information sessions and were subject to all laboratory tests and vaccinations. Participants were given all of their study results in confidential one-to-one counselling sessions.

\section{Results}

The average age of the study participants was $30.5 \mathrm{yrs}$ (median $30 \mathrm{yrs}$, range 18-56 yrs) with a significant gender difference (females: mean 23.1 yrs, range 18-45 yrs; males: mean 32.9 yrs, range $18-56$ yrs, t-test-p $<0.001)$. The mean duration of i.v. drug use for all participants was 8.5 yrs (median 7 yrs, range $0.1-40$ yrs) with females having a significantly shorter history of drug use than males (males: $10.3 \mathrm{yrs}$, females: $3.4 \mathrm{yrs}$, t-test-p $<0.001$ ). The overall life-time history of sharing injection paraphernalia was $62 \%$ (males: $69 \%$, females: $40 \%, \chi^{2}-\mathrm{p}<0.001$ ). When the study population was stratified into groups injecting for $\leq 5 \mathrm{yrs}, 6-9 \mathrm{yrs}$ and $\geq 10 \mathrm{yrs}$, the proportion of those reporting a history of sharing injection paraphernalia was $39.8 \%, 65.8 \%$ and $81.8 \%$ respectively $\left(\chi^{2}-\mathrm{p}<0.001\right)$.

The study revealed that $69 \%$ of all participants had a history of imprisonment (males: $84 \%$, females: $23 \%, \chi^{2}-\mathrm{p}<0.001$ ) with $29 \%$ experiencing $\geq 1$ month of imprisonment and $8 \%$ experiencing $\geq 1$ year. Overall, $14 \%$ of participants (males: $7.7 \%$, females: $33 \%, \chi^{2}-\mathrm{p}<0.001$ ) had exchanged sex for money or drugs in the past and 56\% (males: $58 \%$, females: $49 \%, \chi^{2}$ $\mathrm{p}=0.11$ ) had intra-cutaneous tattoos or a history of ritual cutting.

\section{HIV}

There were 43 participants who were also registered at "SPARSHA Nepal", which is an NGO which exclusively serves people living with HIV. Participants from this centre were excluded from the statistical analysis of HIV prevalence to eliminate this obvious selection bias. An additional 4 participants refused an HIV test. Consequently, 354 participants were included in the analysis of HIV prevalence.

After exclusion of the participants from SPARSHA, the overall HIV prevalence in the cohort was $13.8 \%$ (95\% CI: 10-18\%) (Table 1). The differences were not statistically significantfemales had lower rates than males, and those living in the mid-western Nepalguni region had lower rates than those in the central and eastern regions.

Besides other factors (region and history of sharing injecting paraphernalia), the duration of injecting drug use (in years) was the strongest significant predictor of the presence of anti-HIV 
Table 1. HIV infection stratified by gender and region of Nepal.

\begin{tabular}{|c|c|c|c|c|c|c|c|c|c|c|c|c|}
\hline \multirow[b]{2}{*}{$M / F$} & \multicolumn{3}{|l|}{ All } & \multicolumn{3}{|c|}{ Eastern Region } & \multicolumn{3}{|c|}{ Central Region } & \multicolumn{3}{|c|}{ Nepalgunj } \\
\hline & All & M & $\mathbf{F}$ & All & M & $\mathbf{F}$ & All & M & $\mathbf{F}$ & All & $\mathbf{M}$ & $\mathbf{F}$ \\
\hline n & 354 & 254 & 100 & 139 & 70 & 69 & 136 & 108 & 28 & 79 & 76 & 3 \\
\hline$\%$ & $100 \%$ & $72 \%$ & $28 \%$ & $39 \%$ & $20 \%$ & $19 \%$ & $38 \%$ & $31 \%$ & $8 \%$ & $22 \%$ & $21 \%$ & $0.9 \%$ \\
\hline HIV & 49 & 40 & 9 & 21 & 12 & 9 & 22 & 22 & 0 & 6 & 6 & 0 \\
\hline No HIV & 305 & 214 & 91 & 118 & 58 & 60 & 114 & 86 & 28 & 73 & 70 & 3 \\
\hline HIV (\%) & $13.8 \%$ & $15.7 \%$ & $9.0 \%$ & $15.1 \%$ & $17.1 \%$ & $13.0 \%$ & $16.2 \%$ & $20.4 \%$ & $0.0 \%$ & $7.6 \%$ & $7.9 \%$ & $0.0 \%$ \\
\hline $95 \% \mathrm{Cl}$ & $10-18 \%$ & $12-21 \%$ & $5-16 \%$ & $10-22 \%$ & $10-28 \%$ & $7-23 \%$ & $11-23 \%$ & $14-29 \%$ & $0-12 \%$ & $4-16 \%$ & $4-16 \%$ & $0-56 \%$ \\
\hline
\end{tabular}

M: male, F: female, $95 \% \mathrm{Cl}: 95 \%$-confidence interval. $\mathrm{n}=354$. Gender difference (male vs. female) for HIV non-significant, $\chi^{2}-\mathrm{p}=0.18$. Regional difference (Nepalgunj vs. 'other') for HIV non- significant $\chi^{2}-p=0.07$.

doi:10.1371/journal.pone.0134455.t001

antibodies in a logistic regression model $(\operatorname{Exp}(B) 1,215, \mathrm{p}<0.001)$. When stratified into groups of people injecting for $\leq 5 \mathrm{yrs}, 6-9 \mathrm{yrs}$ and $\geq 10 \mathrm{yrs}$, the prevalence of anti-HIV antibodies was $3.6 \%, 13.9 \%$ and $43.6 \%$, respectively $\left(\chi^{2}-\mathrm{p}<0.001\right)$.

\section{HBV}

Lifetime exposure to HBV (anti-HBc antibodies) was found in $43.8 \%$ of the study population (95\% CI: 39-49\%). Besides other factors (age and region), the duration of injecting drug use (in years) was the strongest significant predictor of presence of anti-HBc antibodies in a logistic regression model $(\operatorname{Exp}(B) 1,178, \mathrm{p}<0.001)$. When stratified in groups of people injecting for $\leq 5 \mathrm{yrs}, 6-9 \mathrm{yrs}$ and $\geq 10 \mathrm{yrs}$, the prevalence of anti-HBc antibodies was $22.4 \%, 43.8 \%$ and $65.4 \%$, respectively $\left(\chi^{2}-\mathrm{p}<0.001\right)$. The overall HBV prevalence (HBsAg positive) was $3.5 \%$ (95\% CI: $2-6 \%)$ (Table 2) with a non-significant trend $(\mathrm{p}=0.07)$ towards higher rates in the Terai regions (Biratnagar and Dharan in the eastern region and Nepalgunj in western region) versus the central region (Lalitpur and Kathmandu). Of the 401 participants, 78 (19.5\%) had anti-HBs antibodies as markers of naturally- or vaccination-acquired immunity.

A total of $31 \%$ of all HBsAg-negative participants showed an "isolated anti-HBc antibodies" pattern (i.e. anti-HBc antibody positive and $\mathrm{HBsAg} /$ anti-HBs antibody negative), and $6.3 \%$ of all participants tested positive for isolated anti-HBs antibodies after vaccination. Of the 26 people who stated having been vaccinated against $\mathrm{HBV}$ in the past, the following results were observed: 2 (7.7\%) were HBsAg postive, 4 (15.4\%) were isolated anti-HBc antibody carriers, 6

Table 2. HBV infection stratified by gender and region of Nepal.

\begin{tabular}{|c|c|c|c|c|c|c|c|c|c|c|c|c|}
\hline \multirow[b]{2}{*}{$M / F$} & \multicolumn{3}{|l|}{ All } & \multicolumn{3}{|c|}{ Eastern Region } & \multicolumn{3}{|c|}{ Central Region } & \multicolumn{3}{|c|}{ Nepalgunj } \\
\hline & All & M & $\mathbf{F}$ & All & M & $\mathbf{F}$ & All & $M$ & $\mathbf{F}$ & All & M & $\mathbf{F}$ \\
\hline n & 401 & 301 & 100 & 141 & 72 & 69 & 181 & 153 & 28 & 79 & 76 & 3 \\
\hline$\%$ & $100 \%$ & $75 \%$ & $25 \%$ & $35 \%$ & $18 \%$ & $17 \%$ & $45 \%$ & $38 \%$ & $7 \%$ & $20 \%$ & $19 \%$ & $0.75 \%$ \\
\hline HBsAg & 14 & 10 & 4 & 8 & 5 & 3 & 3 & 2 & 1 & 3 & 3 & 0 \\
\hline No HBsAg & 387 & 291 & 96 & 133 & 67 & 66 & 178 & 151 & 27 & 76 & 73 & 3 \\
\hline HBsAg (\%) & $3.5 \%$ & $3.3 \%$ & $4 \%$ & $5.7 \%$ & $6.9 \%$ & $4.3 \%$ & $1.7 \%$ & $1.3 \%$ & $3.6 \%$ & $3.8 \%$ & $3.9 \%$ & $0.0 \%$ \\
\hline $95 \% \mathrm{Cl}$ & $2-6 \%$ & $1.7-6.2 \%$ & $1.5-10 \%$ & & & & & & & & & \\
\hline
\end{tabular}

M: male, F: female, HBsAg: Hepatitis B surface antigen, 95\% Cl: 95\%-confidence interval, $\mathrm{n}=401$. Gender difference (male vs. female) for HBsAg nonsignificant, $\chi^{2}-p=0.75$. Regional difference (Central vs. 'other') for HBsAg non-significant $\chi^{2}-p=0.07$.

doi:10.1371/journal.pone.0134455.t002 
(23.1\%) were naturally immune (anti-HBc and anti-HBs antibodies), and 7 (27\%) had neither anti-HBc nor anti-HBs antibodies. Seven individuals (27\%) had isolated anti-HBs antibodies. Details about HBV/HCV co-infection are discussed in the section below.

Antiretroviral treatment with 3TC and/or TDF is the standard first line therapy for HIV in Nepal. 3TC and/or TDF are induce HBs-seroconversion within 7 years in up to $10 \%$ of people with chronic HBV-infection [33]. However, we did not assess levels of ART use for the study participants. Among all participants with anti-HBc antibodies and known HIV status, HBsAg was present in 5 of the $70 \mathrm{HIV}$-positive (7.1\%) participants and 9 of the $103 \mathrm{HIV}$-negative $(8.7 \%)$ participants (Fisher's exact-p $=0.78$ ).

\section{$\mathrm{HCV}$}

The overall prevalence of anti-HCV antibodies in the tested population was $49.9 \%$. Besides other factors (age, region, history of imprisonment and history of sharing injection paraphernalia) the duration of i.v. drug use (in years) was the strongest significant predictor for the presence of anti-HCV antibodies in a logistic regression $(\operatorname{Exp}(B) 1,326, \mathrm{p}<0.001)$. When stratified into groups of people injecting for $\leq 5 \mathrm{yrs}, 6-9 \mathrm{yrs}$ and $\geq 10 \mathrm{yrs}$, prevalence of anti-HCV antibodies was $19.3 \%, 46.6 \%$ and $84.3 \%$, respectively $\left(\chi^{2}-\mathrm{p}<0.001\right)$.

The prevalence of HCV-RNA was $41.9 \%$ (95\% CI: $37-47 \%)$ with significantly higher rates in the central and eastern regions than in the western region (Nepalgunj) $\left(49.7 \%\right.$ vs $16.5 \%, \chi^{2}$ $\mathrm{p}<0.01$ ) (Table 3). HCV-RNA prevalence correlated significantly with age (Fig 1). A logistic regression analysis was used to analyse the factors associated with HCV infection and to predict the HCV-RNA positivity. Independent variables included (1) history of imprisonment, (2) duration of injecting drug use, (3) age, (4) region, (5) gender and (6) HIV status (Table 4).

A test of the full model against a constant-only model was statistically significant indicating that the predictors reliably distinguished between those who were living with HCV and those who were not $\left(\chi^{2}=277.7, \mathrm{p}<0.001\right.$ with $\left.\mathrm{df}=7\right)$. A Nagelkerke's $\mathrm{R}^{2}$ of 0.69 indicated that there was a moderately strong relationship between prediction and grouping. A Hosmer and Lemeshow test produced a $\mathrm{p}=0.775$, indicating that the model provided a good fit to the data. The Wald criterion demonstrated that all parameters made a significant contribution to the model prediction $(\mathrm{p} \leq 0.001)$. Seven "outliers" were removed from the model. The prediction formula was given as:

$$
\mathrm{p}=\frac{\mathrm{e}^{(-5.997+0.15 \times \text { Started }+1.563 \times \text { Prison }+0.084 \times \text { Age }+3.142 \times \text { East }+2,464 \times \text { Central }+1 \times \text { Western }+2.764 \times \text { HIV }-1.968 \times \text { Female })}}{1+\mathrm{e}^{(-5.997+0.15 \times \text { Started }+1.563 \times \text { Prison }+0.084 \times \text { Age }+3.142 \times \text { East }+2,464 \times \text { Central }+1 \times \text { Western }+2.764 \times \text { HIV }-1.968 \times \text { Female })}}
$$

Prediction success was $86.5 \%$ (91.2\% for HCV-negativity and 80\% for HCV-positivity) with an overall cut-off value of $\mathrm{p}=0.5$.

\section{Persistence and spontaneous clearance of HCV}

Of the 200 patients who were reactive for anti-HCV antibodies, 32 (16\%, 95\% CI: 12-22\%) experienced spontaneous HCV-clearance (anti-HCV positive and HCV-RNA negative). This spontaneous clearance occurred in $43.5 \%$ of those $\leq 24$ yrs (Fig 2). In a logistic regression model for all participants with anti-HCV antibodies, the persistence of HCV-RNA correlated significantly with age $(\mathrm{p}=0.01, \operatorname{Exp}(\mathrm{B})=1.071,95 \% \mathrm{CI}$ : 1.016-1.128).

The spontaneous HCV clearance rate was significantly lower in people living with HIV (people living without HIV: 21.6\%, 95\% CI: 15-30\%; people living with HIV: 10\%, 95\% CI: $5-18 \%$, Fisher's exact-p $=0.025$ ) (Fig 2). In our study, the gender differences in spontaneous $\mathrm{HCV}$ clearance disappeared when adjusting for age. 
Table 3. HCV infection stratified by gender and region of Nepal.

\begin{tabular}{|c|c|c|c|c|c|c|c|c|c|c|c|c|}
\hline \multirow[b]{2}{*}{$M / F$} & \multicolumn{3}{|l|}{ All } & \multicolumn{3}{|c|}{ Eastern Region } & \multicolumn{3}{|c|}{ Central Region } & \multicolumn{3}{|c|}{ Nepalgunj } \\
\hline & All & M & $\mathbf{F}$ & All & M & $\mathbf{F}$ & All & M & $\mathbf{F}$ & All & M & $\mathbf{F}$ \\
\hline n & 401 & 301 & 100 & 141 & 72 & 69 & 181 & 153 & 28 & 79 & 76 & 3 \\
\hline$\%$ & $100 \%$ & $75 \%$ & $25 \%$ & $35 \%$ & $18 \%$ & $17 \%$ & $45 \%$ & $38 \%$ & $7 \%$ & $20 \%$ & $19 \%$ & $0.75 \%$ \\
\hline HCV naive & 201 & 120 & 81 & 74 & 22 & 52 & 66 & 40 & 26 & 61 & 58 & 3 \\
\hline Anti-HCV-Ab & 200 & 181 & 19 & 67 & 50 & 17 & 115 & 113 & 2 & 18 & 18 & 0 \\
\hline HCV-RNA & 168 & 159 & 9 & 51 & 44 & 7 & 104 & 102 & 2 & 13 & 13 & 0 \\
\hline HCV-RNA(\%) & $41.9 \%$ & $52.8 \%$ & $9.0 \%$ & $36.2 \%$ & $61.1 \%$ & $10.1 \%$ & $57.5 \%$ & $66.7 \%$ & $7.1 \%$ & $16.5 \%$ & $17.1 \%$ & $0 \%$ \\
\hline $95 \% \mathrm{Cl}$ & $37-47 \%$ & $47-58 \%$ & $5-16 \%$ & & & & & & & & & \\
\hline
\end{tabular}

M: male, F: female, AB: antibodies, RNA: ribonucleic acid, 95\% Cl: 95\%-confidence interval, $n=401$. Gender difference (male vs. female) for anti-HCV antibodies and HCV-RNA significant, both: $\chi^{2}-p<0.01$, but the difference is not evident once gender is adjusted for age (see main text). Regional difference (Nepalgunj vs. 'other') for anti-HCV antibodies and HCV-RNA both: significant $\chi^{2}-p<0.01$.

doi:10.1371/journal.pone.0134455.t003

\section{HCV genotypes}

HCV genotypes(HCV-GT) were determined in 164 of the 168 HCV-RNA positive participants and HCV-GT remained undetermined in 4 samples. Of the 164 samples with a determined HCV-GT, 66 were HCV-GT 1 (40.2\%), and 98 were HCV-GT 3 (59.8\%) (Fig 3). There was no significant difference in HCV-GT in terms of gender or region (Table 5). Subtype $3 \mathrm{~b}$ was found exclusively in the eastern region where $25.8 \%$ of all HCV-GT3 infections were caused by subtype $3 \mathrm{~b}$, and the remaining $74.2 \%$ were caused by subtype $3 \mathrm{a}$. All HCV-GT 3 viruses were subtype $3 \mathrm{a}$ in the other two regions and one undefined GT3 subtype was found in the central region. The phylogenetic tree of the 5UTR region (Fig 4) of the HCV isolates showed a genotype-specific clustering within samples and with reference samples from isolates of India, China and Thailand.

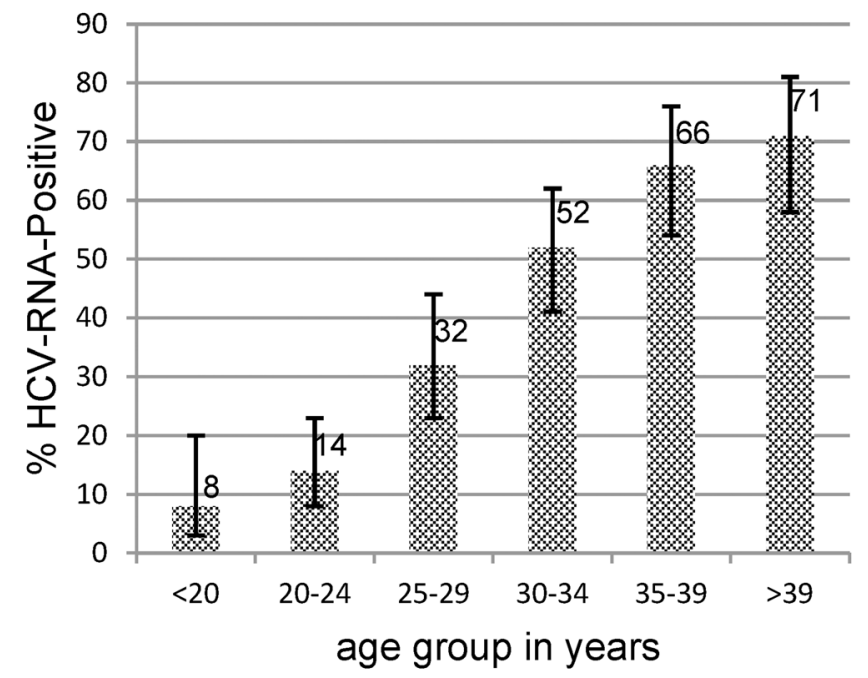

Fig 1. HCV-RNA positivity stratified by age. Rate of HCV-infection is associated with age $\left(\chi^{2}-p<0.001\right.$, error bars show $95 \% \mathrm{Cl}$ ).

doi:10.1371/journal.pone.0134455.g001 
Table 4. Logistic regression model to predict HCV-RNA positivity.

\begin{tabular}{lrrrrrrrr}
\hline & B & S.E. & Wald & df & Sig. & Exp(B) & 95\% Cl for EXP(B) Lower & 95\% Cl for EXP(B) Upper \\
\hline Region & & & 32.166 & 2 & .000 & & & \\
Region(1) & 3.142 & .564 & 31.009 & 1 & .000 & 23.150 & 7.661 & 69.955 \\
Region(2) & 2.464 & .500 & 24.234 & 1 & .000 & 11.750 & 4.406 & 31.337 \\
Age & .084 & .027 & 9.857 & 1 & .002 & 1.088 & 1.032 & 1.146 \\
started & .150 & .037 & 16.473 & 1 & .000 & 1.162 & 1.081 & 1.250 \\
everprison(1) & 1.563 & .492 & 10.092 & 1 & .001 & 4.772 & 1.820 & 12.514 \\
HIV(1) & 2.764 & .578 & 22.853 & 1 & .000 & 15.864 & 5.108 & .140 \\
Gender & -1.968 & .665 & 8.771 & 1 & .003 & .140 & .038 & .514 \\
Constant & -5.997 & 1.468 & 16.695 & 1 & .000 & .002 & & \\
\hline
\end{tabular}

Variables encoded as:

Have you ever been in prison? (Yes = $1 ;$ No $=0)$

How many years ago have you started injecting drugs? In years

What is your age? In years

In which region does the person live? (Region 0: Western (Yes = 1; No = 0); Region 1: Eastern Yes = 1; No = 0); Region 2: Central $($ Yes = 1; No = 0),

Is the person living with HIV? (Yes = 1 ; No $=0)$

Gender? (Female: 1; Male $=0$ )

doi:10.1371/journal.pone.0134455.t004

\section{$\mathrm{HBV} / \mathrm{HCV}$ co-infection and HBV/HCV/HIV triple infection}

Only 3 of the 401 participants were found to have an HBsAg-positive HBV infection and an RNA-positive HCV infection on the day of examination ( $0.75 \%)$. Two of these patients were also living with HIV ("triple infection").

Of all participants who were found to be reactive for anti-HCV antibodies, $70 \%$ of those living with $\mathrm{HBV}$ (HBsAg positive) experienced spontaneous $\mathrm{HCV}$ clearance, while only $13.7 \%$ of HBsAG-negative participants experienced a spontaneous HCV clearance. (Fisher's exact-

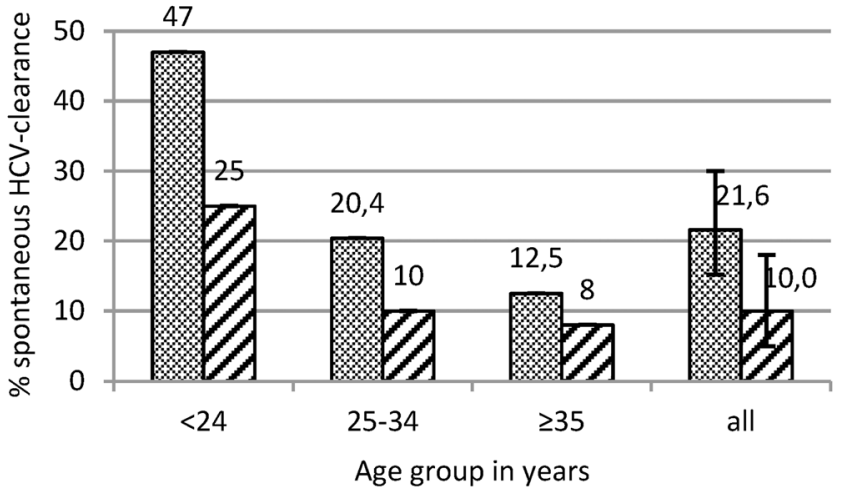

\section{Tspontaneous clearance HIV negative \\ 】 spontaneous clearance HIV positive}

Fig 2. Rate of spontaneous clearance stratified by age and HIV status. Rate of spontaneous clearance of $\mathrm{HCV}$ is associated with age (spontaneous clearance associated with age: $\chi^{2}-p<0.001$ ) and HIV status (spontaneous clearance associated with HIV-status in "all" patients: two-sided Fischer's Exact $p=0.03$, error bars show $95 \% \mathrm{Cl}$ ).

doi:10.1371/journal.pone.0134455.g002 


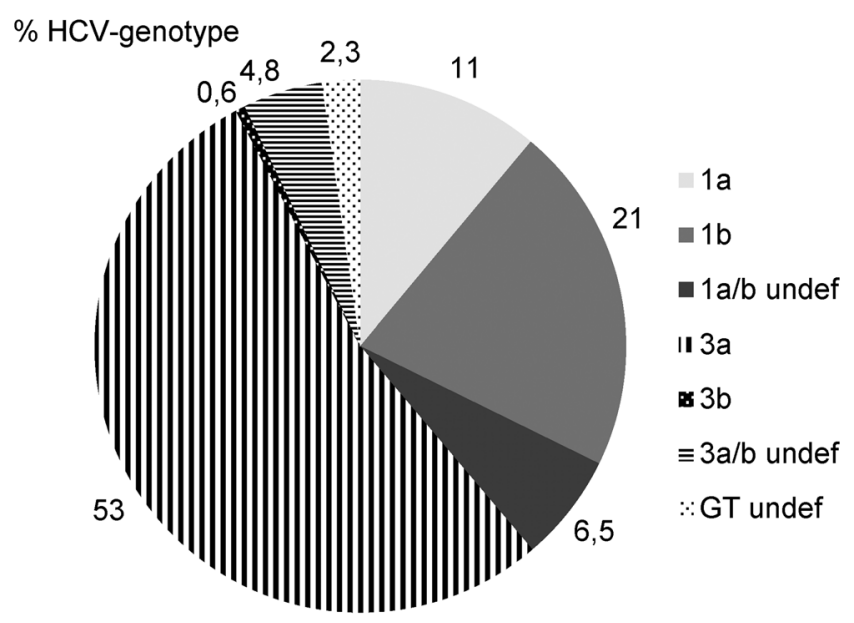

Fig 3. Percentage of HCV genotype-frequencies.

doi:10.1371/journal.pone.0134455.g003

$\mathrm{p}<0.001$ ) (Fig 5). However, HBV-status was not statistically significantly associated with the very high rates of spontaneous $\mathrm{HCV}$-clearance in the age group $\leq 24$ yrs.

When only people with both anti-HBc antibodies and anti-HCV antibodies are analysed ( $\mathrm{n}=140$ ), the "isolated anti-HBc"-pattern was found in $71.6 \%$ of people with HCV-persistence and $41.7 \%$ with spontaneous HCV clearance (Fisher's exact-p $=0.008$ ). HBsAg was diagnosed in $29.2 \%$ of people with spontaneous HCV clearance and $2.6 \%$ of people with HCV-persistence (Fisher's exact-p $<0.001$ ) (Table 6)

\section{HIV/HCV co-infection}

Of the 397 participants with known HIV-status, 72 (18.1\%) were living with an HIV/HCV coinfection (HCV-RNA and anti-HIV-antibodies) (Fig 6). Participants living with HIV had an HCV-RNA-positivity rate of $84.7 \%$, whilst HIV-negative participants showed an HCV-RNApositivity rate of $29.5 \%\left(\chi^{2}-\mathrm{p}<0.001\right)$.

Table 5. HCV-genotypes stratified by gender and region.

\begin{tabular}{|c|c|c|c|c|c|c|c|c|c|c|c|c|}
\hline \multirow[b]{2}{*}{$M / F$} & \multicolumn{3}{|l|}{ All } & \multicolumn{3}{|c|}{ Eastern Region } & \multicolumn{3}{|c|}{ Central Region } & \multicolumn{3}{|c|}{ Nepalgunj } \\
\hline & All & M & $\mathbf{F}$ & All & $\mathbf{M}$ & $\mathbf{F}$ & All & $\mathbf{M}$ & $\mathbf{F}$ & All & $\mathbf{M}$ & $\mathbf{F}$ \\
\hline n & 168 & 159 & 9 & 58 & 44 & 14 & 104 & 102 & 2 & 12 & 12 & 0 \\
\hline$\%$ & $100 \%$ & $91 \%$ & $9.0 \%$ & $33 \%$ & $25 \%$ & $8 \%$ & $60 \%$ & $59 \%$ & $1.1 \%$ & $6,9 \%$ & $6,9 \%$ & $0 \%$ \\
\hline GT1 & 66 & 61 & 5 & 20 & 16 & 4 & 43 & 42 & 1 & 3 & 3 & 0 \\
\hline GT1a & 19 & 18 & 1 & 7 & 6 & 1 & 12 & 12 & 0 & 0 & 0 & 0 \\
\hline GT1b & 11 & 10 & 1 & 4 & 3 & 1 & 5 & 5 & 0 & 2 & 2 & 0 \\
\hline GT1a/b undef & 36 & 33 & 3 & 9 & 7 & 2 & 24 & 24 & 1 & 1 & 1 & 0 \\
\hline GT3 & 98 & 94 & 4 & 31 & 28 & 3 & 57 & 56 & 1 & 10 & 10 & 0 \\
\hline GT3a & 89 & 85 & 4 & 23 & 20 & 3 & 56 & 55 & 1 & 10 & 10 & 0 \\
\hline GT3b & 8 & 8 & 0 & 8 & 8 & 0 & 0 & 0 & 0 & 0 & 0 & 0 \\
\hline GT3a/b undef & 1 & 1 & 0 & 0 & 0 & 0 & 1 & 1 & 0 & 0 & 0 & 0 \\
\hline GTundef & 4 & 4 & 0 & 0 & 0 & 0 & 4 & 4 & 0 & 0 & 0 & 0 \\
\hline
\end{tabular}

M: male, F: female, "undef" = undefined, $n=200$. Gender difference for GT1 vs. 3 non-significant $\chi^{2}-p=0.34$. Regional difference for GT1 vs. 3 nonsignificant $\chi^{2}-p=0.38$.

doi:10.1371/journal.pone.0134455.t005 


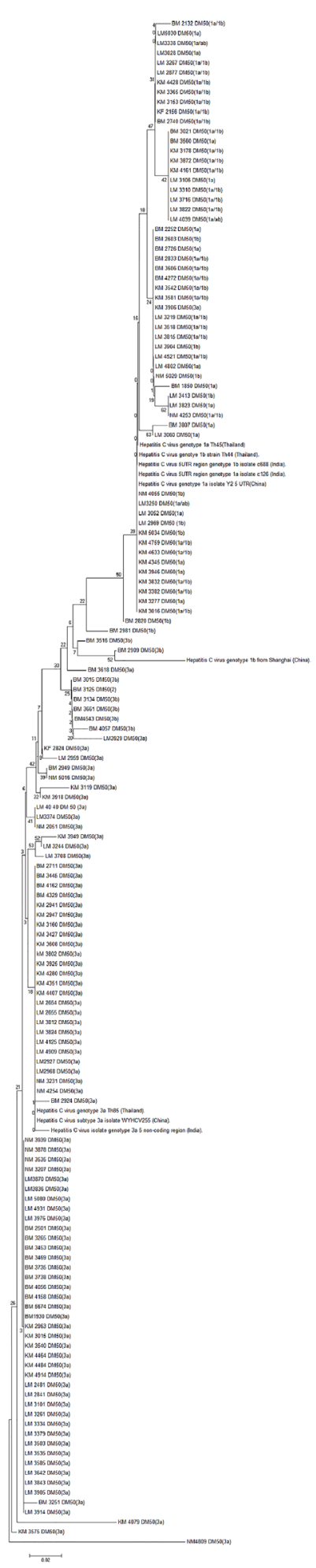

Fig 4. Phylogenetic tree of the 5 UTR region of HCV. The tree is generated by the neighbour-joining method in MEGA 6. The symbol indicates the reference sequences. The first character of the code indicates the origin of the sample (K: Kathmandu, L: Lalitpur, (Central Region), B: Biratnagar (Eastern Region), and N: Nepalgunj (Western Region).

doi:10.1371/journal.pone.0134455.g004 


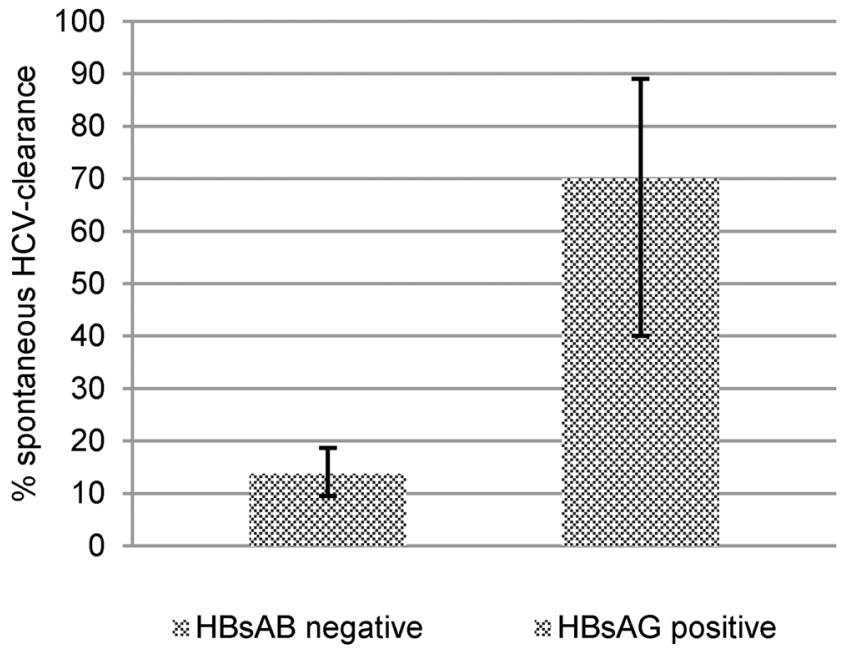

Fig 5. Rate of spontaneous clearance stratified by HBsAg-status. Spontaneous HCV clearance among people living with $\mathrm{HBsAg}$ is significantly higher versus people who are negative for $\mathrm{HBsAg}$. (Two-sided Fisher exact $\mathrm{p}<0.001$, error bars show $95 \% \mathrm{Cl}$ ).

doi:10.1371/journal.pone.0134455.g005

\section{IL28B}

IL28B SNPs rs12979860 and rs8099917 were determined in 122 participants-20 were anti$\mathrm{HCV}$ antibody reactive and HCV-RNA negative ("spontaneous clearance") and 102 were HCV-RNA positive (Table 7). IL28B rs8099917 T/T is associated with a higher rate of spontaneous clearance-all 20 patients with spontaneous clearance (anti-HCV antibody reactive, HCV-RNA negative) had rs8099917 T/T whilst 20 out of 102 (19.7\%) patients currently living with HCV (anti-HCV-antibody reactive, HCV-RNA positive) had IL28B rs8099917 G/T (Fisher's exact-p $=0.04$ ). Participants for the IL28B assessment were selected to examine its effect on the natural course of the HCV-infection. However, the 30 participants with heterozygote IL28B alleles in one or both IL28B SNPs also had a non-significant trend towards impaired clearance of HBsAg versus carriers of IL28B rs12979860-CC/rs8099917-T/T (Fisher's exact$\mathrm{p}=0.09)$.

\section{Discussion}

This study is a baseline assessment to tailor a country-specific response to viral hepatitis among people who inject drugs in Nepal. The results detail the current infection rates among people who inject drugs and seek health care; they do not constitute a nationally representative prevalence survey. Versus national surveillance data (CBS-studies) among people who use drugs, the average age of the participants in our study ( $30.5 \mathrm{yrs})$ is higher than the average age

Table 6. HCV/HBV co-infection.

\begin{tabular}{llll}
\hline & HBV: naturally immune (anti-HBs- and anti-HBc) & HBV: isolated anti-HBc & HBsAG positive \\
\hline HCV-RNA positive $(\mathbf{n}=\mathbf{1 1 6})$ & $30(25.9 \%)$ & $83(71.6 \%)$ & $3(2.6 \%)$ \\
HCV-RNA negative $(\mathbf{n}=\mathbf{2 4})$ & $7(29.2 \%)$ & $10(41.7 \%)$ & $7(29.2 \%)$ \\
\hline
\end{tabular}

All participants with lifetime markers of previous infection of HBV (anti-HBc antibodies) and HCV (anti-HCV antibodies) ( $n=140)$. Isolated-anti-HBc pattern is significantly more frequent in HCV-viraemic participants (Fisher's exact $p=0.008$ ); HBsAg prevalence is significantly more frequent in people with spontaneous HCV-clearance (Fisher's exact $\mathrm{p}<0.001$ ).

doi:10.1371/journal.pone.0134455.t006 


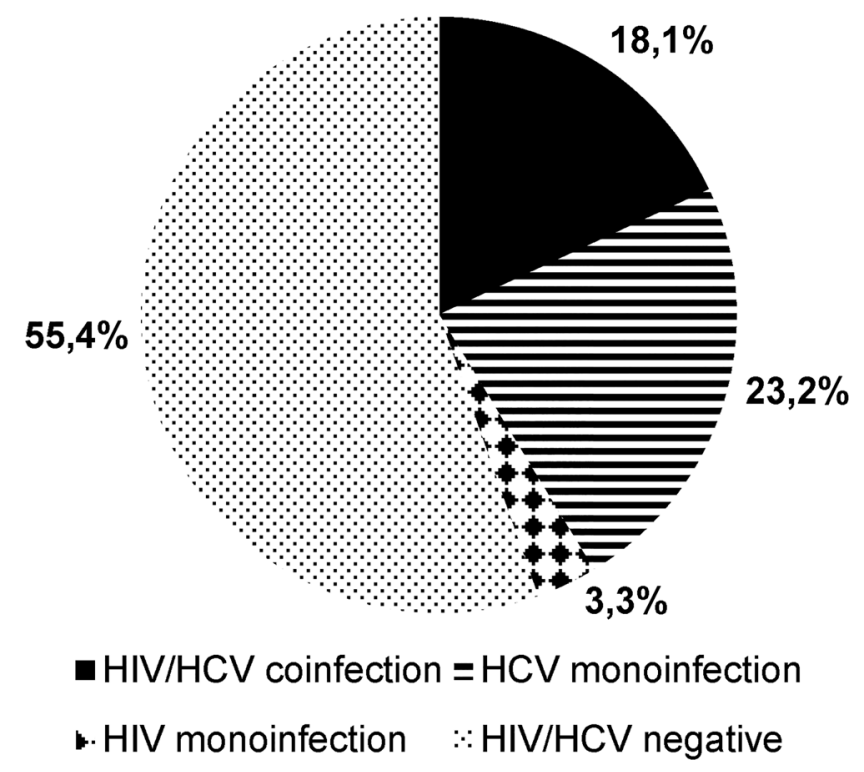

Fig 6. Percentage of frequencies of HIV and HCV mono- and co-infection. At $3.3 \%$, HIV mono-infection is a comparatively rare constellation whereas $\mathrm{HIV} / \mathrm{HCV}$ co-infection is found in $18.1 \%$ of all participants $(\mathrm{n}=397)$.

doi:10.1371/journal.pone.0134455.g006

of all people who inject drugs in Nepal. The average duration of i.v. drug use ( $8.5 \mathrm{yrs})$ is also longer than the average age of those interviewed for the CBS studies (CBS average age is 25.07 yrs with $66 \%$ reporting drug use for $\leq 5 \mathrm{yrs}$ ) [1]. The prevalence rates of HBsAg, HIV and antiHCV antibodies were $3.5 \%, 13.8 \%$ and $49.9 \%$. These figures are 4-, 50- and 100-times higher than the reported national averages. The national figures are mostly based on data from blood donation centres and the "2011-Integrated Biological and Behavioural Surveillance" (IBBS) HIV study [3]. The latter was based on a respondent-driven sample in Pokhara (western region) and Kathmandu. In contrast to our study, this data suggested that the prevalence of HIV among people who inject drugs was as low as $4.6 \%$ and $6.3 \%$ [3].

In comparison to previous studies [22, 23], our estimates for 2013 suggest that the prevalence of anti-HCV antibodies and HCV-RNA is lower-only $49.9 \%$ and $41.9 \%$, respectively. The lower rates of anti-HCV antibodies in our sample could have several explanations: (1) females accounted for $25 \%$ of our study participants whereas the female/male ratio among people who inject drugs in Nepal is usually much lower (e.g. $<5-8 \%$ ) in respondent-driven samples $[1,3]$. In our study, HCV prevalence among women who use drugs was also much lower

Table 7. I28B SNP rs12979860 and rs8099917.

\begin{tabular}{llll}
\hline IL28B & rs8099917 T/T & rs8099917 G/T & rs8099917 G/G \\
\hline rs12979860 C/C & 92 & 1 & 0 \\
$\%(95 \% \mathrm{Cl})$ & $75.4 \%(67-82 \%)$ & $0.8 \%(0.1-4.5 \%)$ & $0 \%$ \\
rs12979860 C/T & 10 & 18 & 0 \\
$\%(95 \% \mathrm{Cl})$ & $8.2 \%(4.5-14 \%)$ & $15 \%(10.5-22 \%)$ & $0 \%$ \\
rs12979860 T/T & 0 & 1 & 0 \\
$\%(95 \% \mathrm{Cl})$ & $0 \%$ & $0.8 \%(0.1-4.5 \%)$ & $0 \%$ \\
\hline
\end{tabular}

$\mathrm{N}=122$

doi:10.1371/journal.pone.0134455.t007 
than among men, which is similar to results from an UNODC study from 2011 that found that 15.2\% of women who inject drugs were anti-HCV antibody positive [24]. (2) The lower HCV prevalence found might also reflect a reduction in $\mathrm{HCV}$ incidence resulting from the establishment of harm-reduction services. Sharing needles with others was reported by only $5 \%$ of participants in 2011, whereas the comparable figures for the Kathmandu valley in 2002 and 2005 were $59 \%$ and $27 \%$, respectively [3]. The idea that there has been a reduction in HCV incidence is supported by the fact that $80.7 \%$ of people in our study who had injected drugs for $\leq 5 \mathrm{yrs}$ had never contracted HCV, whereas $84.3 \%$ of those who had injected for $\geq 10$ yrs had anti$\mathrm{HCV}$ antibodies. Previous assessments found that without preventive interventions, HCV infection usually occurs very quickly after initiation of i.v. drug use $[34,35]$. The low rate of anti-HCV antibodies among people with a history of injecting drugs for $\leq 5 \mathrm{yrs}$ is paralleled by similar reductions in individuals' history of sharing injection paraphernalia as well as lower rates of anti-HIV and anti-HBc antibodies. (3) A persistently high level of mortality is another factor that could account for the comparatively low prevalence of HCV in our study. In 2011, there were 4,722 HIV-related deaths among people living with HIV-this constitutes $9.4 \%$ of the overall number of people living with HIV in Nepal. This is one of the highest proportions of any country in the world [36,37].

Here, we defined a logistic regression formula that enables us to discriminate between those with the highest and lowest pre-test probability of HCV where HCV-laboratory testing is not readily available.

Almost $50 \%$ of people $\leq 24$ yrs who are living with anti-HCV achieved spontaneous clearance (defined as anti-HCV antibody positive but HCV-RNA negative). This rate is higher than the previously reported rates for most other settings or ethnicities $[38,39]$. The high rate of spontaneous clearance could be explained at least in part by the favourable IL28B SNPs [40]. We found favourable IL28B SNP rs 12979860 and rs 8099917 in $76.2 \%$ and $83.6 \%$ of participants; $75 \%$ of participants had favourable variants in both IL28B SNPs. These findings are in line with Firdaus et al.'s study of different population groups in eastern and north-eastern parts of India [30]. We found a significant correlation between IL28B rs8099917 T/T and spontaneous clearance. Because homozygote IL28B rs12979860-C/C and -rs8099917-T/T are associated with high SVR rates after treatment with pegIFN/RBV, our data supports increased availability of HCV-treatment programs [10-13, 30].

The $60: 40 \%$ ratio of HCV-GT3/GT1 among people with RNA-positive HCV infection is also in line with the findings of Firdaus et al. In their work, they reported a $66: 32 \%$ distribution from eastern and north-eastern India [35]. The genotype-specific clustering of the HCV isolates indicates absolute genetic relatedness regardless of geographic origin.

Hepatitis B is a relatively rare infection in Nepal versus the neighbouring countries India and China [41, 42]. The overall prevalence in the general population has repeatedly been found to be $<2 \%$ [43]. This pattern is confirmed by our findings where even in a high-risk population, the prevalence of HBsAg was just 3.3\%. However, we found a high rate of anti-HBc antibodies $(49.1 \%)$ in our cohort, which illustrates an increased risk of infection. It is possible that this mainly occurs during adolescence and adulthood and leads to an acute hepatitis B with subsequent HBsAG clearance. However, our findings also support previous reports that HBV and $\mathrm{HCV}$ can, to a certain degree, suppress each other's replication [34, 40]. Furthermore the high rate of "isolated anti-HBc" patterns especially among people living with HIV or HCV might indicate that there is a relevant proportion of occult HBV infection [44].

$\mathrm{HCV} / \mathrm{HIV}$ co-infection is common, and $18 \%$ of all participants in the study were found to be HIV/HCV co-infected. HIV accelerates the progress of HCV-induced liver disease [9] and putting HIV/HCV co-infected patients on effective ART seems to lessen this effect [45, 46]. While the WHO currently states that no general recommendation can be given to start ART 
earlier in patients living with HCV/HIV co-infection [47], it is important to include HCV care into the spectrum of services for people living with HIV. This is especially true in Nepal: $85 \%$ of all people who inject drugs and live with HIV were co-infected with HCV, and only 13 (3.3\%) of the 397 HIV-tested participants presented with an HIV mono-infection.

In conclusion, the study shows that the potential HCV treatment needs for people who inject drugs in Nepal are lower in absolute numbers than anticipated. Furthermore, we infer that it is reasonable to expect high SVR rates for treatment with pegIFN/RBV because most patients living with HCV are infected with GT3 and have a combination of favourable IL28B SNPs. Finally, we conclude that HCV/HIV co-infection is frequent in Nepal whereas HIV mono-infection is rare. As such, all people living with HIV should be screened, diagnosed and evaluated for HCV therapy. Clinicians should consider initiating ART shortly after infection.

\section{Limitations}

The study sample does not constitute a representative sample of all people who use or inject drugs in Nepal. The study only covers individuals living in Dharan, Biratnagar, Kathmandu, Lalitpur, Chitwan, and Nepalgunj. However, there are also other places with non-ignorable numbers of people who use drugs (Pokhara, Budwal, Birganj and the far-western region). The sample is also not representative for all people who inject drugs in the regions where our study was conducted. In particular, the study sample over-represents females and only includes people with health-care seeking behaviour. As a consequence, the study tends to include older participants with a comparatively longer duration of i.v. drug use. It is likely that our HIV-

prevalence estimate is actually rather conservative because we excluded participants registered with SPARSHA for the estimation of HIV-prevalence. This is especially true when considering HIV-prevalence in the central valley (Kathmandu and Lalitpur) where people living with HIV are mainly concentrated at SPARSHA.

The technique that was used to sequence a $150 \mathrm{bp}$ sequence of the 5'UTR region of the viral genome failed to define HCV GT in 4 of the $168 \mathrm{HCV}$-RNA positive samples.

\section{Author Contributions}

Conceived and designed the experiments: HK DK JS SM SP PK DS RT PKC AR SD. Performed the experiments: HK DK JS SM SP PK DS RT PKC AR SD. Analyzed the data: HK DK JS SM SP PK DS RT PKC AR SD. Contributed reagents/materials/analysis tools: HK DK JS SM SP PK DS RT PKC AR SD. Wrote the paper: HK DK JS SM SP PK DS RT PKC AR SD. Obtained ethical approval for research: HK PK DS RT SD.

\section{References}

1. Government of Nepal Central Bureau of Statistics (2014) Survey Report on Current Hard Drug Users in Nepal-2069. Kathmandu: Ministry of Home Affairs Drug Control Programme. 51 p. Available: http:// www.aidsdatahub.org/Survey-Report-on-Current-Hard-Drug-Users-in-Nepal-2013. Accessed 17 October 2014.

2. Ojha SP, Sigdel S, Meyer-Thompson HG, Oechsler H, Verthein U (2014) 'South Asian cocktail'-the concurrent use of opioids, benzodiazepines and antihistamines among injecting drug users in Nepal and associations with HIV risk behaviour. Harm Reduct J 11: 17. doi: 10.1186/1477-7517-11-17 PMID: 24886095

3. NCASC and ASHA Project (2011) Integrated Biological and Behavioral Surveillance (IBBS) Survey among Injecting Drugs Users in Kathmandu Valley, Nepal—Round V. Kathmandu: NCASC. 107 p Available: http://www.aidsdatahub.org/sites/default/files/documents/IBBS_2011_IDU_Kathmandu.pdf. Accessed 17 October 2014.

4. Csete J, Elliot R, Fischer B (2008) "Viral Time Bomb": Health and Human Rights Challenges in Addressing Hepatitis C in Canada. Toronto: Canadian HIV/AIDS Legal Network, Centre for Addictions 
Research of BC and Centre for Applied Research in Mental Health and Addiction. Available: https:// dspace.library.uvic.ca:8443/handle/1828/4796? show = full. Accessed 17 October 2014.

5. Gibson A, Randall D, Degenhardt L (2011) The increasing mortality burden of liver disease among opioid-dependent people: Cohort study. Addiction 106(12): 2186-92. doi: 10.1111/j.1360-0443.2011. 03575.x PMID: 21749525

6. Grebely J, Raffa JD, Lai C, Kerr T, Fischer B, Krajden M, et al. (2011) Impact of hepatitis C virus infection on all-cause and liver-related mortality in a large community-based cohort of inner city residents. $J$ Viral Hepat 18(1): 32-41. doi: 10.1111/j.1365-2893.2010.01279.x PMID: 20196806

7. Ly KN, Xing J, Klevens RM, Jiles RB, Ward JW, Holmberg SD (2012) The increasing burden of mortality from viral hepatitis in the United States between 1999 and 2007. Ann Intern Med 156(4): 271-8. doi: 10.7326/0003-4819-156-4-201202210-00004 PMID: 22351712

8. Danta M, Brown D, Bhagani S, Pybus OG, Sabin CA, Nelson M, et al. (2007) Recent epidemic of acute hepatitis $C$ virus in HIV-positive men who have sex with men linked to high-risk sexual behaviours. AIDS 21(8): 983-91. PMID: 17457092

9. Mauss S, Berg T, Rockstroh J, Sarrazin C, Wedemeyer H (2013) Short Guide to Hepatitis C. Flying Publisher \& Kamps. $178 p$.

10. Jia Z, Ding Y, Tian S, Niu J, Jiang J (2012) Test of IL28B polymorphisms in chronic hepatitis C patients treated with PegIFN and ribavirin depends on HCV genotypes: Results from a meta-analysis. PLoS One 7(9): e45698. doi: 10.1371/journal.pone.0045698 PMID: 23029188

11. Wu LS, Wang H, Geng XP (2012) Two IL28B polymorphisms are associated with the treatment response of different genotypes of hepatitis $C$ in different racial populations: $A$ meta-analysis. Exp Ther Med 3(2): 200-206. PMID: 22969869

12. Jiménez-Sousa MA, Fernández-Rodríguez A, Guzmán-Fulgencio M, García-Álvarez M, Resino S (2013) Meta-analysis: implications of interleukin-28B polymorphisms in spontaneous and treatmentrelated clearance for patients with hepatitis C. BMC Med 11: 6. doi: 10.1186/1741-7015-11-6 PMID: 23298311

13. Guo X, Zhao Z, Xie J, Cai Q, Zhang X, Peng L, et al. (2012) Prediction of response to pegylated-interferon- $\alpha$ and ribavirin therapy in Chinese patients infected with different hepatitis $C$ virus genotype. Virol J 9: 123. doi: 10.1186/1743-422X-9-123 PMID: 22713131

14. Rai SK, Shibata H, Satoh M, Murakoso K, Sumi K, Kubo T, et al. (1994) Seroprevalence of hepatitis B and $C$ viruses in eastern Nepal. Kansenshogaku Zasshi, 68(12): 1492-7. PMID: 7533201

15. Shrestha SM, Subedi NB, Shrestha S, Maharjan KG, Tsuda F, Okamoto H (1998) Epidemiology of hepatitis $C$ virus infection in Nepal. Trop Gastroenterol 19(3): 102-4. PMID: 9828707

16. Sawayama Y, Hayashi J, Ariyama I, Furusyo N, Kawasaki T, Kawasaki M, et al. (1999) A ten year serological survey of hepatitis A, B and C viruses infections in Nepal. J Epidemiol 9(5): 350-4. PMID: 10616269

17. Chander A, Pahwa VK (2003) Status of infectious disease markers among blood donors in a teaching hospital, Bhairahawa, western Nepal. J Commun Dis 35(3): 188-97. PMID: 15796411

18. Karki S, Ghimire P, Tiwari BR, Maharjan A, Rajkarnikar M (2008) Trends in hepatitis B and hepatitis C seroprevalence among Nepalese blood donors. Jpn J Infect Dis 61(4): 324-6. PMID: 18653982

19. Karki S, Ghimire P, Tiwari BR, Rajkarnikar M (2008) Seroprevalence of anti HCV antibodies among blood donors in Kathmandu valley, Nepal. Kathmandu Univ Med J (KUMJ) 6(24): 491-6.

20. Shrestha AC, Ghimire P, Tiwari BR, Rajkarnikar M (2009) Transfusion-transmissible infections among blood donors in Kathmandu, Nepal. J Infect Dev Ctries 3(10): 794-7. PMID: 20009282

21. Tiwari BR, Ghimire P, Kandel SR, Rajkarnikar M (2010) Seroprevalence of HBV and HCV in blood donors: A study from regional blood transfusion services of Nepal. Asian J Transfus Sci 4(2): 91-3. doi: 10.4103/0973-6247.67026 PMID: 20859506

22. Shrestha SM, Shrestha DM, Gafney TE, Maharjan KG, Tsuda F, Okamoto H (1996) Hepatitis B and C infection among drug abusers in Nepal. Trop Gastroenterol 17(4): 212-3. PMID: 9094859

23. Shrestha IL (2003) Seroprevalence of antibodies to hepatitis $C$ virus among injecting drug users from Kathmandu. Kathmandu Univ Med J (KUMJ) 1(2): 101-3.

24. United Nations Office on Drugs \& Crime (UNODC) (2011) Profile, Drug Use Pattern, Risk Behavior \& Selected Bio-Markers of Women Drug Users From Seven Sites in Nepal. Pulchowk: UNODC Press. 68 p. Available: http://www.unodc.org/documents/southasia/reports/Profile_Drug_use_pattern_Risk Behavior_and_selected_Bio-markers_of_women_drug_users_from_seven_sites_in_Nepal.pdf. Accessed 17 October 2014

25. Yu ML, Huang CF, Huang JF, Chang NC, Yang JF, Lin ZY, et al. (2011) Role of interleukin-28B polymorphisms in the treatment of hepatitis $C$ virus genotype 2 infection in Asian patients. Hepatology 53 (1): 7-13. doi: 10.1002/hep.23976 PMID: 21254157 
26. Sinn DH, Kim YJ, Lee ST, Gwak GY, Choi MS, Lee JH, et al. (2011) Association of a single nucleotide polymorphism near the interleukin-28B gene with response to hepatitis $\mathrm{C}$ therapy in Asian patients. $\mathrm{J}$ Gastroenterol Hepatol 26: 1374-9. doi: 10.1111/j.1440-1746.2011.06744.x PMID: 21501223

27. Hayes CN, Kobayashi M, Akuta N, Suzuki F, Kumada H, Abe H, et al. (2011) HCV substitutions and IL28B polymorphisms on outcome of peg-interferon plus ribavirin combination therapy. Gut 60(2): 261-7. doi: 10.1136/gut.2010.223495 PMID: 21068134

28. Kawaoka T, Hayes CN, Ohishi W, Ochi H, Maekawa T, Abe H, et al. (2011) Predictive value of the IL28B polymorphism on the effect of interferon therapy in chronic hepatitis $\mathrm{C}$ patients with genotypes 2a and 2b. J Hepatol 54(3): 408-14. doi: 10.1016/j.jhep.2010.07.032 PMID: 21112660

29. Sivaprasad S, Rao PN, Gupta R, Ashwini K, Reddy DN (2012) The distribution of genotype and allelic frequency of IL28B gene polymorphism in Andhra Pradesh, India. J Clin Exp Hepatol 2(2): 112-5. doi: 10.1016/S0973-6883(12)60098-X PMID: 25755419

30. Firdaus R, Biswas A, Saha K, Mukherjee A, Chaudhuri S, Chandra A, et al. (2014) Impact of host IL28B rs12979860, rs8099917 in interferon responsiveness and advanced liver disease in chronic genotype 3 hepatitis C patients. PLoS One 9(6): e99126. doi: 10.1371/journal.pone.0099126 PMID: 24914551

31. Shrestha SM, Shrestha S (2012) Chronic hepatitis B in Nepal: an Asian country with low prevalence of HBV infection. Trop Gastroenterol 33(2): 95-101. PMID: 23025054

32. Murphy DG, Willems B, Deschênes M, Hilzenrat N, Mousseau R, Sabbah S (2007) Use of sequence analysis of the NS5B region for routine genotyping of hepatitis $C$ virus with reference to $C / E 1$ and $5^{\prime}$ untranslated region sequences. J Clin Microbiol 45(4): 1102-12. PMID: 17287328

33. Marcellin P, Gane EJ, Tsai N, Flisiak R, Petersen J, Gurel S, et al.(2013) Seven Years of Treatment with Tenofovir DF for Chronic Hepatitis B virus infection is safe and well tolerated and associated with sustained virological, biochemical, and serological responses with no detectable resistance. 64th Annual Meeting of the American Association for the Study of Liver Diseases (AASLD 2013). Washington, DC, November 1-5, 2013. Abstract 926. Available: http://www.natap.org/2013/AASLD/AASLD_94. htm. Accessed 17 July 2015.

34. Thomas DL, Vlahov D, Solomon L, Cohn S, Taylor E, Garfein R, et al. (1995) Correlates of hepatitis C virus infections among injection drug users. Medicine (Baltimore) 74(4): 212-20.

35. Garfein RS, Vlahov D, Galai N, Doherty MC, Nelson KE (1996) Viral infections in short-term injection drug users: the prevalence of the hepatitis $C$, hepatitis $B$, human immunodeficiency, and human T-lymphotropic viruses. Am J Public Health 86(5): 655-61. PMID: 8629715

36. World Health Organization (2011) Global Health Observatory Data Repository. Available: http://apps. who.int/gho/data/node. main.618?lang = en. Accessed 17 October 2014.

37. Government of Nepal, National Center for AIDS and STD Control (2012) National Estimates of HIV Infections in Nepal. Teku, Kathmandu. Available: http://aidsdatahub.org/dmdocuments/National_ Estimate_of_HIV_2012.pdf Accessed 17 October 2014.

38. Thomas DL, Astemborski J, Rai RM, Anania FA, Schaeffer M, Galai N, et al. (2000) The natural history of hepatitis $C$ virus infection: Host, viral, and environmental factors. JAMA 284(4): 450-6. PMID: 10904508

39. Micallef JM1, Kaldor JM, Dore GJ (2006) Spontaneous viral clearance following acute hepatitis C infection: a systematic review of longitudinal studies. J Viral Hepat 13(1): 34-41. PMID: 16364080

40. Kong F, Pan Y, Chi X, Wang X, Chen L, Lv J, et al. (2014) Factors associated with spontaneous clearance of hepatitis $C$ virus in Chinese population. Biomed Res Int 2014: 527030 doi: 10.1155/2014/ 527030 PMID: 25133165

41. Behal R, Jain R, Behal KK, Bhagoliwal A, Aggarwal N, Dhole TN (2008) Seroprevalence and risk factors for hepatitis B virus infection among general population in Northern India. Arq Gastroenterol 45(2): 137-40. PMID: 18622468

42. Liang X, Bi S, Yang W, Wang L, Cui G, Cui F, et al. (2009) Epidemiological serosurvey of hepatitis B in China-declining HBV prevalence due to hepatitis B vaccination. Vaccine 27(47): 6550-7. doi: 10.1016/ j.vaccine.2009.08.048 PMID: 19729084

43. Shrestha SM, Shrestha S (2012) Chronic hepatitis B in Nepal: An Asian country with low prevalence of HBV infection. Trop Gastroenterol 33(2): 95-101. PMID: 23025054

44. Khamduang W, Ngo-Giang-Huong N, Gaudy-Graffin C, Jourdain G, Suwankornsakul W, Jarupanich T, et al. (2013) Prevalence, risk factors, and impact of isolated antibody to hepatitis B core antigen and occult hepatitis B virus infection in HIV-1-infected pregnant women. Clin Infect Dis 56(12): 1704-12. doi: 10.1093/cid/cit166 PMID: 23487379

45. Verma S, Wang CH, Govindarajan S, Kanel G, Squires K, Bonacini M (2006) Do type and duration of antiretroviral therapy attenuate liver fibrosis in HIV-hepatitis C virus-co-infected patients? Clin Infect Dis 42(2): 262-70. PMID: 16355339 
46. Vogel M, Rockstroh JK (2009) Liver disease: the effects of HIV and antiretroviral therapy and the implications for early antiretroviral therapy initiation. Curr Opin HIV AIDS 4(3): 171-5. doi: $10.1097 / \mathrm{COH}$. Ob013e328329c602 PMID: 19532046

47. World Health Organization (2014) Guidelines for the screening, care and treatment of persons with hepatitis C infection. Geneva: WHO Press. 124 p. 